\title{
BMJ Open Processes of care and outcomes for homeless patients hospitalised for cardiovascular conditions at safety-net versus non-safety-net hospitals: cross- sectional study
}

\author{
Atsushi Miyawaki (D) ,1,2 Dhruv Khullar, ${ }^{3,4}$ Yusuke Tsugawa (1) 5,6
}

To cite: Miyawaki A, Khullar D, Tsugawa Y. Processes of care and outcomes for homeless patients hospitalised for cardiovascular conditions at safety-net versus nonsafety-net hospitals: crosssectional study. BMJ Open 2021;11:e046959. doi:10.1136/ bmjopen-2020-046959

- Prepublication history and additional supplemental material for this paper are available online. To view these files, please visit the journal online (http://dx.doi.org/10.1136/ bmjopen-2020-046959).

Received 15 November 2020

Revised 11 March 2021 Accepted 16 March 2021
Check for updates

(C) Author(s) (or their employer(s)) 2021. Re-use permitted under CC BY-NC. No commercial re-use. See rights and permissions. Published by BMJ.

For numbered affiliations see end of article.

Correspondence to

Dr Atsushi Miyawaki;

amiyawaki-tky@umin.ac.jp

\section{ABSTRACT}

Objectives Evidence suggests that homeless patients experience worse quality of care and poorer health outcomes across a range of medical conditions. It remains unclear, however, whether differences in care delivery at safety-net versus non-safety-net hospitals explain these disparities. We aimed to investigate whether homeless versus non-homeless adults hospitalised for cardiovascular conditions (acute myocardial infarction (AMI) and stroke) experience differences in care delivery and health outcomes at safety-net versus non-safety-net hospitals.

Design Cross-sectional study.

Setting Data including all hospital admissions in four states (Florida, Massachusetts, Maryland, and New York) in 2014.

Participants We analysed 167105 adults aged 18 years or older hospitalised for cardiovascular conditions (age mean=64.5 years; 75361 (45.1\%) women; 2123 (1.3\%) homeless hospitalisations) discharged from 348 hospitals. Outcome measures Risk-adjusted diagnostic and therapeutic procedure and in-hospital mortality, after adjusting for patient characteristics and state and quarter fixed effects.

Results At safety-net hospitals, homeless adults hospitalised for AMI were less likely to receive coronary angiogram (adjusted OR (aOR), 0.42; 95\% Cl, 0.36 to 0.50; $\mathrm{p}<0.001)$, percutaneous coronary intervention ( $\mathrm{aOR}, 0.52$; $95 \% \mathrm{Cl}, 0.44$ to $0.62 ; \mathrm{p}<0.001)$ and coronary artery bypass graft (aOR, $0.43 ; 95 \% \mathrm{Cl}, 0.26$ to $0.71 ; \mathrm{p}<0.01)$ compared with non-homeless adults. Homeless patients treated for strokes at safety-net hospitals were less likely to receive cerebral arteriography (aOR, $0.23 ; 95 \% \mathrm{Cl}, 0.16$ to 0.34 ; $\mathrm{p}<0.001$ ), but were as likely to receive thrombolysis therapy. At non-safety-net hospitals, we found no evidence that the probability of receiving these procedures differed between homeless and non-homeless adults hospitalised for AMI or stroke. Finally, there were no differences in inhospital mortality rates for homeless versus non-homeless patients at either safety-net or non-safety-net hospitals. Conclusion Disparities in receipt of diagnostic and therapeutic procedures for homeless patients with cardiovascular conditions were observed only at safetynet hospitals. However, we found no evidence that these differences influenced in-hospital mortality markedly.
Strengths and limitations of this study

- To investigate disparities in cardiovascular care and outcomes for homeless versus non-homeless patients by the hospital safety-net status, we analysed the combined data, including all hospital admissions and the hospital characteristics in four US states.

- The states in our sample represented approximately $30 \%$ of the US homeless population.

- We could not fully account for unmeasured confounders that might be related to processes of care among homeless adults, such as the severity of certain medical or psychosocial conditions.

- We were unable to identify mechanisms for why the disparity in care intensity was observed at safetynet hospitals but not non-safety-net hospitals.

\section{INTRODUCTION}

An estimated 3.5 million Americans experience homelessness annually, ${ }^{1}$ and 1 in 25 US adults experience homelessness during their lifetimes. ${ }^{2}$ Homelessness is defined by the US Department of Housing and Urban Development as lacking 'a fixed, regular, and adequate nighttime residence'. ${ }^{3}$ It also includes those at imminent risk of homelessness and individuals fleeing domestic violence. Homeless individuals suffer high levels of medical and psychiatric illnesses ${ }^{45}$ and face substantial barriers to meeting basic social and healthcare needs, leading to high rates of premature disability and death. ${ }^{6}$ Cardiovascular disease-a leading cause of death and disability for all populations-is particularly burdensome for homeless individuals, ${ }^{7}$ who have less access to the preventive and routine care needed to effectively manage these conditions and tend to have more cardiovascular risk factors. ${ }^{58}$ Compared with the general population, homeless individuals have higher rates of hypertension, 
diabetes, dyslipidaemia, ${ }^{9}$ smoking, ${ }^{9}{ }^{10}$ substance use disorder $^{9} 11$ and unhealthy diet, ${ }^{12}$ and they are two to five times more likely to die of cardiovascular disease. ${ }^{813}$ Understanding the mechanisms for these disparities, and what can be done to narrow them, is critical for improving outcomes for homeless populations.

Research has found that homeless patients experience poor transitional care, ${ }^{14}$ which may lead to suboptimal patterns of healthcare utilisation, including early and frequent readmissions. ${ }^{15} 16$ The extent to which homeless patients with cardiovascular conditions also receive different in-hospital care remains incompletely characterised, but one recent study found that they were less likely to undergo diagnostic and therapeutic procedures and more likely to experience in-hospital death. ${ }^{17}$ Little is known, however, about whether these disparities differ by the type of hospital in which homeless patients are cared for.

To address this knowledge gap, in this study, we investigated whether care delivery and health outcomes for homeless patients differed by whether they were cared for at safety-net versus non-safety-net hospitals. Safety-net hospitals provide care to patients regardless of ability to pay and treat many poor and underserved patients, including those who are homeless. ${ }^{18}$ While safety-net hospitals play a vital role in the US healthcare system, they are often under-resourced, ${ }^{19}$ and some prior work has shown the lower quality of care at safety-net versus non-safety-net hospitals, including for cardiovascular care ${ }^{19-25}$ It is not clear, however, whether differences in care delivered at safety-net institutions influence outcomes for homeless patients with cardiovascular disease.

Using statewide databases of all hospital admissions in four large, diverse states, we sought to answer three key questions. First, are homeless adults less likely to undergo diagnostic and therapeutic procedures at safety-net and non-safety-net hospitals compared with non-homeless adults? Second, if so, do these disparities differ by the cardiovascular condition for which patients were hospitalised? Lastly, do homeless adults hospitalised for cardiovascular conditions experience higher in-hospital mortality rates at safety-net and non-safety-net hospitals?

\section{METHODS}

\section{Data sources}

This cross-sectional study used the 2014 State Inpatient Database (SID) from four states (Florida, Maryland, Massachusetts and New York). The SID data were collected by the Healthcare Cost and Utilization Project of the Agency for Healthcare Research and Quality (AHRQ). ${ }^{26}$ The AHRQ collected these data through statewide data organisation for each state, to which hospitals were required to submit hospital claims data at discharge, including clinical and demographic information. ${ }^{27}$ The SID includes all inpatient discharge records from acute care hospitals in a state, regardless of the source of hospital admission or insurance status. These four states were selected because of their geographic and sociodemographic diversity, as well as the availability of the homeless indicator and unique patient identifier. ${ }^{28}{ }^{28}$ The states in our sample represent approximately $30 \%$ of the US homeless population in $2014 .^{29}$ We incorporated data on hospital characteristics from Medicare Provider Cost Report files ${ }^{30}$ (for the Medicare disproportionate share hospital (DSH) patient percentage) and the AHA Annual Survey database ${ }^{31}$ (for teaching status, profit status, ruralurban commuting area (RUCA) classification, hospital size and the presence of a medical or cardiac intensive care unit (ICU)).

\section{Study sample}

We included all adults aged 18 years or older who were discharged dead or alive from acute care hospitals in 2014 with three primary diagnoses: (1) acute myocardial infarction (AMI) and (2) stroke. Each primary diagnosis of cardiovascular conditions was identified using the International Classification of Diseases, Ninth Revision, Clinical Modification codes (the codes for each condition are shown in online supplemental table A1 in the online supplemental material). ${ }^{1732}$ Of the 194144 hospitalisations in our initial sample, we excluded 27009 hospitalisations $(13.9 \%)$ with missing data on at least one of exposure, outcome or adjustment variables stated below (The missing data were observed primarily for the following three variables: hospital safety-net status, homeless status and race/ethnicity, for which 20167 $(10.4 \%), 4173(2.1 \%)$ and $4101(2.1 \%)$ hospitalisations had missing data, respectively). Excluding patients with missing race/ethnicity would be important because it was considered as a confounder in the relationship between homelessness and receipt of procedures and in-hospital mortality. ${ }^{5}$ Our final analytic sample consisted of 167105 hospital discharges.

\section{Exposure variables}

The primary exposure variables of interest were (1) homeless status (homeless vs non-homeless) and (2) hospital safety-net status (safety-net vs non-safety-net). The SID includes the indicator variable for homeless status directly reported by hospital staff at the time of death or discharge alive and has been used in previous AHRQ reports ${ }^{33} 34$ and in other studies. ${ }^{1728}{ }^{35}$ Since this identification of homeless status is based on information collected at hospital discharge, it represents the homelessness at the time of hospitalisations.

We defined 'safety-net hospital' using the Medicare DSH patient percentage, which is a measure the proportion of Medicaid and uninsured individuals a hospital serves. ${ }^{36}$ We defined safety-net hospitals as those in the highest decile of DSH patient percentage; the remaining $90 \%$ of hospitals were classified as non-safety-net hospitals. ${ }^{37}$

\section{Outcome variables}

The outcomes of interest were (1) receipt of diagnostic and therapeutic procedures, and (2) in-hospital mortality 
after hospitalisation for each cardiovascular condition. Diagnostic and therapeutic procedures included coronary angiogram, PCI and coronary artery bypass grafting (CABG) for AMI; and cerebral arteriography and thrombolysis for stroke. Outcomes were also examined by type of AMI (ST-elevation myocardial infarction (STEMI) or non-ST-elevation myocardial infarction (non-STEMI)) and by type of stroke (haemorrhagic or ischaemic).

\section{Adjustment variables}

We adjusted for patient characteristics and state and quarter fixed effects. Patient characteristics include age, sex, race and ethnicity (non-Hispanic white, non-Hispanic black, Hispanic and other), the primary payer (Medicare, Medicaid, private insurance, self-pay and other) and indicator variables for 29 comorbidities included in Elixhauser comorbidity index (derived from the same hospitalisation) ${ }^{38}$ State and quarter fixed effects account for both measured and unmeasured (time-invariant) characteristics of states and quarter (time trend), allowing us to effectively compare patient outcomes within the same state and quarter. ${ }^{39}$

\section{Statistical analysis}

First, we compared (1) patient characteristics and proportion of being treated at safety-net hospitals between homeless and non-homeless patients hospitalised for cardiovascular conditions, and (2) hospital characteristics between safety-net hospitals and nonsafety-net hospitals. Second, we constructed a multivariable logistic regression model with the interaction term between patients' homelessness and treating hospitals' safety-net status. We adjusted for patient characteristics (stated in the 'Adjustment variables' subsection) and state and quarter fixed effects. We formally tested the interaction between homeless status and hospital safety-net status using a Wald test. SEs were clustered at the hospital-level to account for a potential correlation of patients treated at the same hospital. ${ }^{39}$ To account for multiple comparisons, we considered a $\mathrm{p}$ value $<0.025$ as statistically significant (homeless vs non-homeless at safety-net and non-safety-net hospitals). This calculation was conducted for each cardiovascular condition and then repeated for subtypes of each condition (eg, STEMI or non-STEMI).

Finally, we calculated the risk-adjusted rates of diagnostic/therapeutic procedures and in-hospital death for each of four patient groups (homeless patients at safety-net hospitals, homeless patients at non-safety-net hospitals, non-homeless patients at safety-net hospitals and non-homeless patients at non-safety-net hospitals) using marginal standardisation form of predictive margins; for each hospitalisation, we calculated predicted probabilities of undergoing procedures with patient homeless status and hospital safety-net status fixed at each level and then averaged over the distribution of covariates in our sample. $^{40}$

\section{Secondary analyses}

We conducted a series of secondary analyses. First, to examine how hospital characteristics contribute to associations between safety-net status and homeless and non-homeless patients' outcomes, we further adjusted for hospital characteristics including the profit status (for-profit, non-profit and public), RUCA (urban, suburban, large rural and small rural), hospital size (large (400+beds), medium (100-399 beds) and small (1-99 beds) ) and the presence of a medical or cardiac ICU. ${ }^{41}$ Second, we examined alternative cut-offs to define hospital safety-net status, whereby we considered hospitals in the highest quartile of DSH patient percentage as safety-net hospitals. ${ }^{42-44}$ Finally, we conducted a sensitivity analysis in which we included all the missing as a separate category (eg, non-Hispanic white, non-Hispanic black, Hispanic, others and 'missing' in the race/ethnicity category). All the analyses were conducted by using Stata V.15 (StataCorp, 2017).

\section{Patient and public involvement}

Data were derived from administrative records, so no patients were involved in setting the research question or the outcome measures nor were they involved in developing plans or implementation of the study. No patients were asked to advise on interpretation or writing up of results.

\section{RESULTS}

\section{Baseline characteristics}

Of 167105 hospitalisations for cardiovascular conditions in our sample, 2123 (1.3\%) occurred among patients who were homeless. Homeless patients were, on average, younger, more likely to be racial and ethnic minorities, enrolled in Medicaid and have diabetes and substance use disorders (table 1). We found that around $90 \%$ of homeless hospitalisations occurred at safety-net hospitals.

\section{Characteristics of safety-net hospitals and non-safety-net hospitals}

The DSH patient percentage differed substantially for safety-net hospitals versus non-safety-net hospitals (median, $48 \%$ vs 12\%) (table 2). Safety-net hospitals were more likely to be public, medium-size, for-profit and teaching hospitals located in urban areas. The presence of an MICU or CICU and the distribution of yearly number of hospitalisations for AMI/stroke were similar between safety-net and non-safety-net hospitals.

\section{Homeless patients with AMI}

We found that homeless patients hospitalised for AMI were less likely to undergo coronary angiogram compared with non-homeless patients at safety-net hospitals (adjusted procedure rate, $37.7 \%$ for homeless patients vs $55.6 \%$ for non-homeless patients; adjusted OR (aOR), $0.42 ; 95 \%$ CI, 0.36 to 0.50 ; $\mathrm{p}<0.001$ ), PCI ( $25.7 \%$ vs $37.8 \%$; aOR, 0.52 ; $95 \% \mathrm{CI}, 0.44$ to $0.62 ; \mathrm{p}<0.001)$ and $\mathrm{CABG}(2.7 \%$ vs $5.7 \%$; 
Table 1 Characteristics of hospitalisations for cardiovascular diseases

\begin{tabular}{|c|c|c|c|}
\hline \multirow[b]{2}{*}{ Characteristics } & \multicolumn{3}{|c|}{ Patients, no (\%) } \\
\hline & $\begin{array}{l}\text { Homeless } \\
(n=2123)\end{array}$ & $\begin{array}{l}\text { Non-homeless } \\
(n=164982)\end{array}$ & $\begin{array}{l}\text { Overall } \\
(n=167105)\end{array}$ \\
\hline Acute myocardial infarction & $974(44.8)$ & 83294 (49.6) & $84268(49.5)$ \\
\hline Non-STEMI & 776 (35.7) & $60454(36.0)$ & $61230(36.0)$ \\
\hline STEMI & $198(9.1)$ & $22840(13.6)$ & 23038 (13.5) \\
\hline Stroke & 1149 (52.9) & $81688(48.6)$ & 82837 (48.6) \\
\hline Haemorrhagic & $304(14.0)$ & $17641(10.5)$ & 17945 (10.5) \\
\hline Ischaemic & 845 (38.9) & $64047(38.1)$ & $64892(38.1)$ \\
\hline Age, mean (SD), years & $64.5(14.5)$ & $69.6(14.5)$ & $69.5(14.5)$ \\
\hline Female sex & 968 (45.6) & $74393(45.1)$ & $75361(45.1)$ \\
\hline \multicolumn{4}{|l|}{ Race/ethnicity } \\
\hline Non-Hispanic white & 406 (19.1) & 108648 (65.9) & $109054(65.3)$ \\
\hline Non-Hispanic black & $674(31.8)$ & $26020(15.8)$ & 26694 (16.0) \\
\hline Hispanic & $519(24.5)$ & $17581(10.7)$ & $18100(10.8)$ \\
\hline Others & $524(24.7)$ & $12733(7.7)$ & $13257(7.9)$ \\
\hline \multicolumn{4}{|l|}{ Insurance } \\
\hline Medicare & $858(40.4)$ & $15948(64.2)$ & $106806(63.9)$ \\
\hline Medicaid & $1132(53.3)$ & $16604(10.1)$ & $17736(10.6)$ \\
\hline Private & $48(2.3)$ & $33913(20.6)$ & 33961 (20.3) \\
\hline Self-pay & $85(4.0)$ & $8517(5.2)$ & $8602(5.2)$ \\
\hline \multicolumn{4}{|l|}{ Comorbidities (selected) } \\
\hline Congestive heart failure & $436(20.5)$ & $40681(24.7)$ & $41117(24.6)$ \\
\hline Valvular disease & $122(5.8)$ & $22389(13.6)$ & 22511 (13.5) \\
\hline Peripheral vascular disease & $101(4.8)$ & $17454(10.6)$ & 17555 (10.5) \\
\hline Hypertension & $1712(80.6)$ & $132701(80.4)$ & $134413(80.4)$ \\
\hline Diabetes & 945 (44.5) & 61337 (37.2) & $62282(37.3)$ \\
\hline Renal failure & 371 (17.5) & 30448 (18.5) & 30819 (18.4) \\
\hline Alcohol abuse & 169 (8.0) & 7150 (4.3) & 7319 (4.4) \\
\hline Drug abuse & 177 (8.3) & 5255 (3.2) & 5432 (3.3) \\
\hline Treated at safety-net hospitals & $1928(90.8)$ & $11606(7.0)$ & $13534(8.1)$ \\
\hline
\end{tabular}

STEMI, ST-elevation myocardial infarction.; .

aOR, 0.43; $95 \% \mathrm{CI}, 0.26$ to $0.71 ; \mathrm{p}<0.01$ ), after adjusting for patient characteristics and state and quarter fixed effects (figure 1 and online supplemental table A2). In the subgroups of patients with non-STEMI, homeless patients had lower odds of coronary angiogram $(33.5 \%$ vs $48.5 \%$; aOR, 0.48 ; $95 \%$ CI, 0.40 to 0.58 ; $\mathrm{p}<0.001)$, PCI ( $17.1 \%$ vs $26.9 \%$; aOR, 0.53 ; $95 \%$ CI, 0.43 to 0.66 ; $\mathrm{p}<0.001$ ) and $\mathrm{CABG}(2.9 \%$ vs $6.3 \%$; aOR, $0.41 ; 95 \% \mathrm{CI}, 0.24$ to $0.71 ; \mathrm{p}<0.01)$ compared with non-homeless patients. In the subgroup of STEMI patients, the trend was similar, though the difference was statistically significant only for coronary angiogram $(54.5 \%$ vs $75.1 \%$; aOR, $0.33 ; 95 \% \mathrm{CI}$, 0.23 to $0.47 ; \mathrm{p}<0.001)$. We found no evidence of differences in in-hospital mortality rate between homeless and non-homeless patients with AMI at safety-net hospitals.
At non-safety-net hospitals, we found no differences in the odds of receiving coronary angiogram, PCI or CABG for homeless versus non-homeless patients hospitalised for AMI, including STEMI or non-STEMI. The formal test of interaction between homeless status and safety-net status was statistically significant for a coronary angiogram $(p<0.01)$, indicating that the disparity in care intensity between homeless and non-homeless patients differed by hospital safety-net status (online supplemental table A2). We found no evidence that in-hospital mortality differed between homeless and non-homeless patients with AMI at non-safety-net hospitals.

\section{Homeless patients with stroke}

Among adults hospitalised for stroke, homeless adults were less likely to receive cerebral arteriography $(2.4 \%$ vs 
Table 2 Hospital characteristics

\begin{tabular}{|c|c|c|c|}
\hline \multirow[b]{2}{*}{ Characteristics } & \multicolumn{3}{|l|}{ Hospitals, No (\%) } \\
\hline & $\begin{array}{l}\text { Safety-net hospitals } \\
(n=36)\end{array}$ & $\begin{array}{l}\text { Non-safety-net hospitals } \\
(n=312)\end{array}$ & $\begin{array}{l}\text { Overall } \\
(n=348)\end{array}$ \\
\hline Small (1-99 beds) & $1(2.8)$ & $46(14.7)$ & $47(13.5)$ \\
\hline Medium (100-299 beds) & $25(69.4)$ & $186(59.6)$ & $211(60.6)$ \\
\hline Major teaching & $5(13.9)$ & $41(13.1)$ & $46(13.2)$ \\
\hline Minor teaching & $18(50.0)$ & $104(33.3)$ & $122(35.1)$ \\
\hline Non-teaching & $13(36.1)$ & $167(53.5)$ & $180(51.7)$ \\
\hline \multicolumn{4}{|l|}{ Profit status } \\
\hline \multicolumn{4}{|l|}{$\mathrm{RUCA}^{*}$} \\
\hline Urban & $36(100.0)$ & $237(77.0)$ & $273(79.4)$ \\
\hline Suburban & $0(0.0)$ & $18(5.8)$ & $18(5.2)$ \\
\hline Large rural & $0(0.0)$ & $35(11.4)$ & $35(10.2)$ \\
\hline Small rural & $0(0.0)$ & $18(5.8)$ & $18(5.2)$ \\
\hline Medical ICU & $28(77.8)$ & $242(77.6)$ & $270(77.6)$ \\
\hline Cardiac ICU & $15(41.7)$ & $146(46.8)$ & $161(46.3)$ \\
\hline DSH percentage, median (IQR) & $48(38-60)$ & $12(7-19)$ & $12(8-24)$ \\
\hline \multicolumn{4}{|c|}{ No of hospitalisations/year, median (IQR)† } \\
\hline
\end{tabular}

${ }^{*}$ RUCA codes were missing for four non-safety-net hospitals.

†The numbers of hospitalisations for acute myocardial infarction and stroke recorded for each hospital in 2014 were summarised overall and by hospital safety-net status.

.DSH, disproportionate share hospitals; ICU, intensive care unit; RUCA, rural-urban commuting area.

8.7\%; aOR, 0.23; 95\% CI, 0.16 to 0.34; $\mathrm{p}<0.001$ ) (figure 2 and online supplemental table A3). This pattern was similar for individuals with haemorrhagic stroke $(7.8 \%$ vs $16.2 \%$; aOR, $0.37 ; 95 \% \mathrm{CI}, 0.23$ to $0.60 ; \mathrm{p}<0.001)$ and ischaemic stroke $(0.9 \%$ vs $6.5 \%$; aOR, $0.12 ; 95 \% \mathrm{CI}, 0.06$ to $0.24 ; \mathrm{p}<0.001)$.

At safety-net hospitals, homeless adults with ischaemic stroke were as likely to undergo thrombolysis as nonhomeless adults $(7.8 \%$ vs $9.0 \%$; aOR, $0.90 ; 95 \% \mathrm{CI}, 0.38$ to $2.11 ; \mathrm{p}=0.80$ ). We found no evidence of differences in in-hospital mortality between homeless and non-homeless adults hospitalised for stroke at safety-net hospitals.

At non-safety-net hospitals, we found no evidence that the probability of receiving cerebral arteriography or thrombolysis differed between homeless versus nonhomeless adults hospitalised for stroke (including both haemorrhagic and ischaemic stroke). The formal test of interaction between homeless status and safety-net status was statistically significant for cerebral arteriography among overall patients and patients who had an ischaemic stroke $(p<0.01)$. We found no evidence that in-hospital mortality rates differed between homeless and non-homeless adults hospitalised for stroke at nonsafety-net hospitals.

\section{Secondary analyses}

Our findings were qualitatively unaffected after additional adjustment for hospital characteristics, although the interaction between homeless status and safety-net status for cerebral arteriography was no longer statistically significant for overall hospitalisations for stroke (online supplemental table A4 and table A5). Nevertheless, the patterns underlying how less likely homeless adults were to underwent procedures compared with non-homeless adults were similar at both safety-net and non-safety-net hospitals. Our findings were also not sensitive to using the alternative definition of hospital safety-net status (considering safety-net hospitals to be in the top quartile of the DSH patient percentage) (online supplemental table A6 


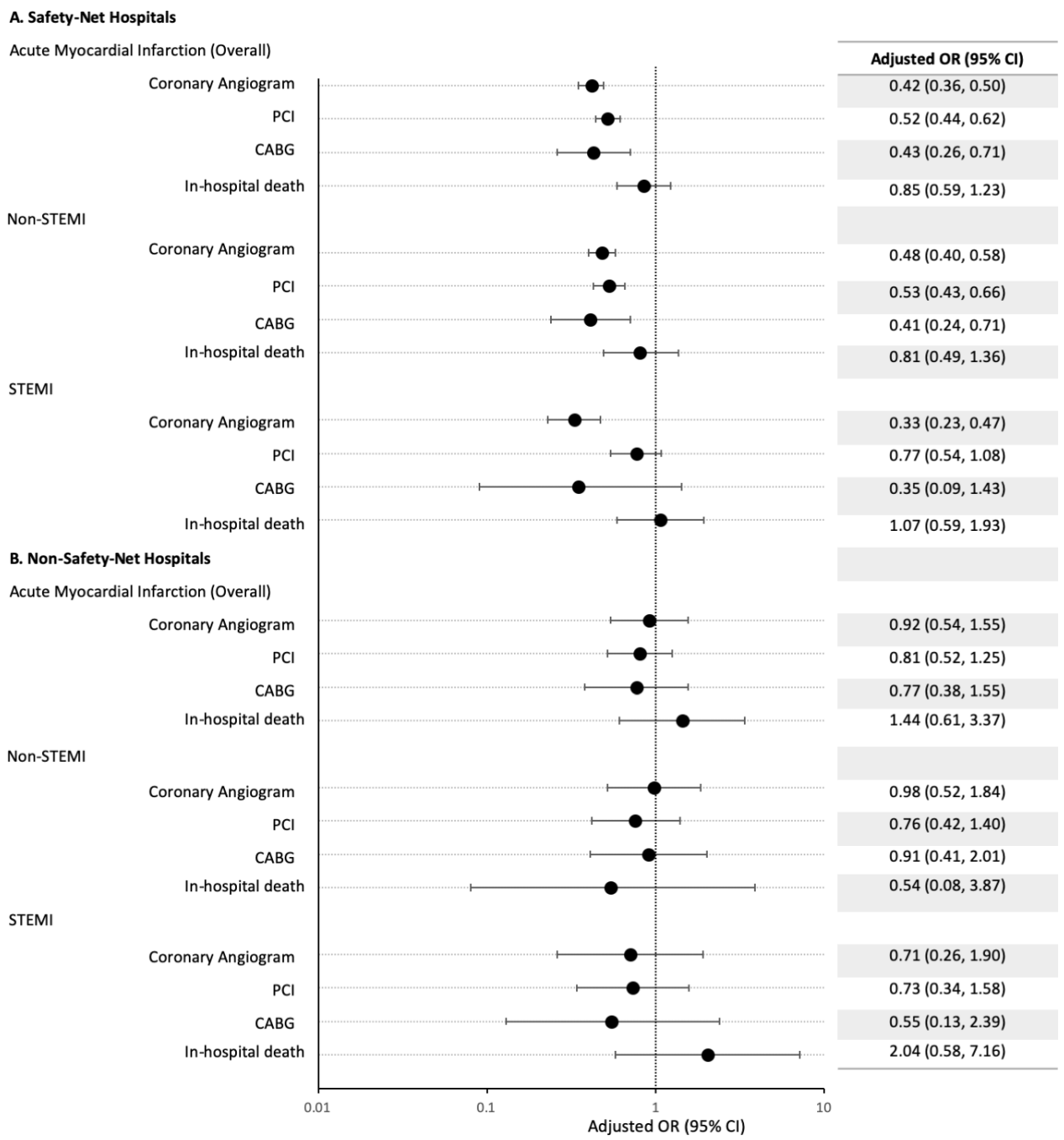

Figure 1 Risk-adjusted ORs of diagnostic/therapeutic procedures and in-hospital death for homeless adults hospitalised for AMI compared with non-homeless adults at safety-net and non-safety-net hospitals. For both safety-net and non-safetynet hospitals, adjusted ORs (black circles) for diagnostic and therapeutic procedures and in-hospital death among homeless patients (vs non-homeless patients) are presented with $95 \% \mathrm{Cls}$ (horizontal lines). We used multivariate logistic regression adjusted for patient characteristics (including the primary diagnosis at index admission, age, sex, race/ethnicity, primary payers and comorbidities) and quarter and state indicator variables (quarter and state fixed-effects). AMI, acute myocardial infarction; CABG, Coronary artery bypass grafting; PCI, percutaneous coronary intervention; STEMI, ST-elevation myocardial infarction.

and table A7) and including all the missing as a separate category (online supplemental table A8 and table A9).

\section{DISCUSSION}

In this study of hospitalisations for cardiovascular conditions across four diverse states, we found that homeless adults were less likely to receive diagnostic and therapeutic procedures at safety-net but not non-safety-net hospitals. Specifically, at safety-net hospitals, homeless adults hospitalised for AMI were less likely to receive coronary angiogram, PCI or CABG; those presenting with stroke were less likely to receive cerebral angiography. However, in-hospital mortality rates did not differ from homeless or non-homeless adults at either safety-net or non-safety-net hospitals.

It is unclear why these disparities exist at safety-net hospitals, but there may be several potential mechanisms.
First, many safety-net hospitals have relatively few financial and human resources compared with non-safety-net hospitals, resulting in inadvertent disparities in care delivery. ${ }^{18}$ Second, homeless individuals may be thought less likely to be able to adhere to needed follow-up care after certain procedures (eg, antiplatelet therapy after PCI). Third, homeless patients may experience delays in receiving healthcare services and, therefore, may be less likely to benefit from certain procedures. Fourth, homeless adults hospitalised at safety-net hospitals might have more frequent admissions. ${ }^{45}$ If they were hospitalised for AMI or stroke recently and already received diagnostic/ therapeutic procedures, they might be less likely to receive a repeated procedure in a subsequent hospitalisation.

While homeless adults underwent procedures at lower rates at safety-net hospitals, we did not find marked differences in in-hospital mortality. These results may suggest 


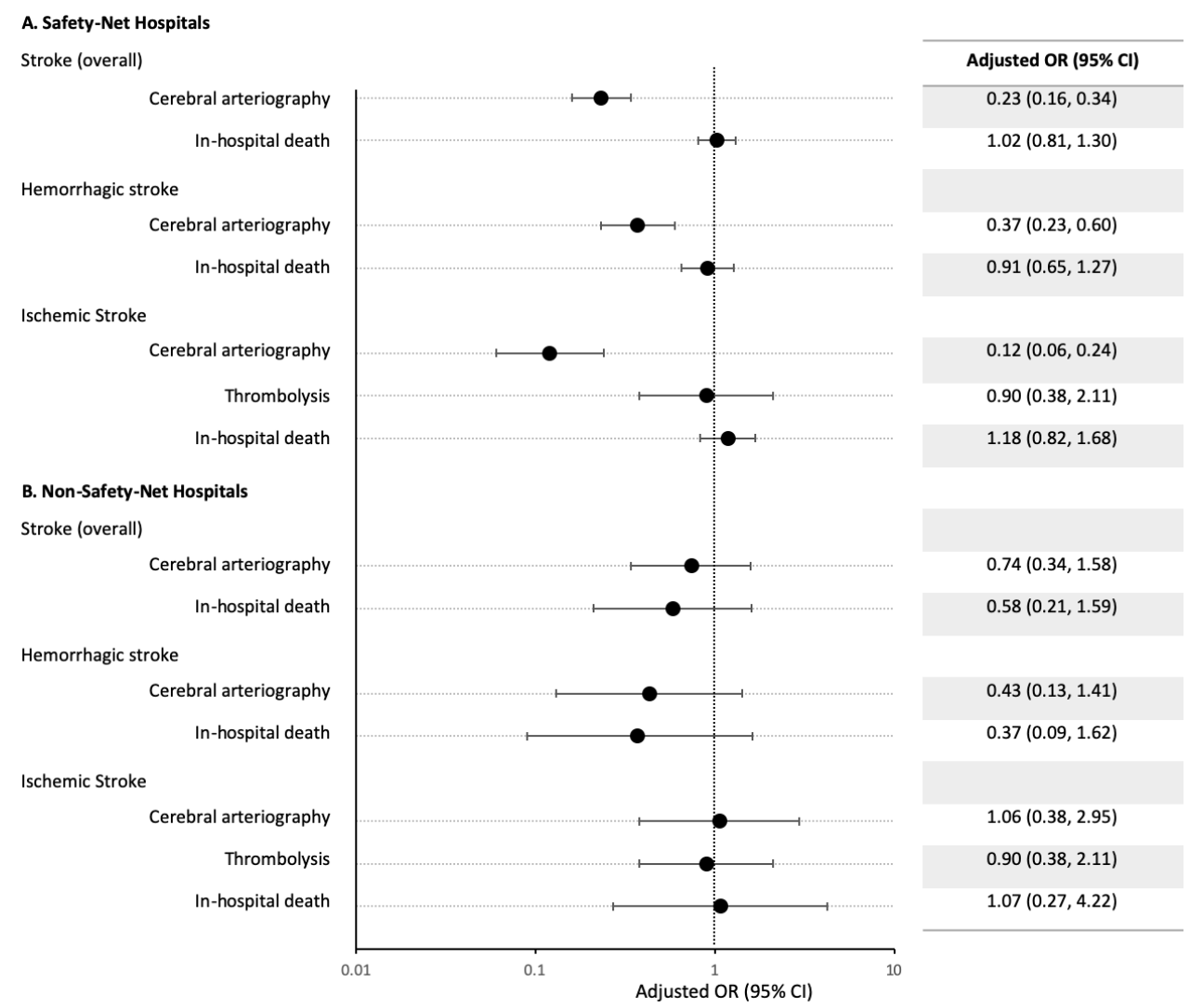

Figure 2 Risk-adjusted ORs of diagnostic/therapeutic procedures and in-hospital death for homeless adults hospitalised for stroke compared with non-homeless adults at safety-net and non-safety-net hospitals. For both safety-net and non-safetynet hospitals, adjusted ORs (black circles) for diagnostic and therapeutic procedures and in-hospital death among homeless patients (vs non-homeless patients) are presented with $95 \% \mathrm{Cls}$ (horizontal lines). We used multivariate logistic regression adjusted for patient characteristics (including the primary diagnosis at index admission, age, sex, race/ethnicity, primary payers and comorbidities) and quarter and state indicator variables (quarter and state fixed-effects).

that fewer procedures may not necessarily increase in-hospital mortality rates, though other recent studies have found associations between procedure rate and in-hospital mortality rate in the general population hospitalised with cardiovascular conditions. ${ }^{46}{ }^{47}$ Given that the only patient outcome we were able to assess was in-hospital mortality rate, however, it is possible that lack of diagnostic or therapeutic procedures influences other immediate outcomes-such functional status or longer-term outcomes like disability and mortality at 1 year-which should be studied in future research.

Our findings are consistent with prior research, suggesting that homeless patients experience a lower intensity of care compared with non-homeless patients. ${ }^{5} 1417$ A qualitative study conducted in Connecticut reported a lack of coordination between hospitals and social services at discharge for homeless patients. ${ }^{14}$ Another study found that homeless compared with non-homeless patients were less likely to receive diagnostic and therapeutic care in hospitalisations for cardiovascular conditions. ${ }^{17}$ These lower intensity of care among homeless patients were considered attributable to several factors, including social/financial barriers, housing and transportation challenges, alcohol abuse or mental illness, discrimination within the healthcare system and inadequate social support after receiving care. ${ }^{5}$ However, how the characteristics of hospitals where homeless patients received care, especially hospital safety-net status, affected these care intensity disparities. Our study aims to address this issue and suggests that for homeless adults hospitalised for cardiovascular conditions, some proportion of disparities may be explained by where they seek care. While safety-net hospitals play a vital role in the health system, by providing care to vulnerable, low-income and homeless populations, the disparity in procedure rates for acute cardiovascular conditions warrants further exploration.

Our study has limitations. First, as with any observational study, we could not fully account for unmeasured confounders. Homeless patients might be less likely to undergo diagnostic/therapeutic procedures at safety-net hospitals due to unobserved variables, such as the severity of certain medical or psychosocial conditions and unrecorded comorbidities that could affect the indication for procedures. However, if this was the case, we would expect disparities in care intensity to be found at non-safety-net hospitals as well. Second, it is possible that some homeless and non-homeless individuals were misclassified because data on the homelessness were provided directly by hospitals to states in SID databases; we feel that homeless patients may be coded as non-homeless, but the likelihood 
that many non-homeless patients are coded as homeless is low. This misclassification would introduce bias towards the null, and the true disparity would be larger than our estimate. Moreover, the definition of homeless status used in this study was based on the information collected at a single point of hospital discharge, and therefore, our findings would under-represent persons who moved between homelessness and their dwellings (ie, temporary/secondary homelessness). Third, given the relatively small sample sizes of homeless adults at non-safety-net hospitals in the current analysis, it was possible that we were underpowered to detect any meaningful differences in patient outcomes, especially for some of the analyses speculating on differences in in-hospital mortality rates (combined with low event rate) or focusing on subclassified conditions (eg, STEMI). Given that we were unable to distinguish the lack of power versus truly non-different outcomes, non-significant results in some of our analyses should be interpreted with caution. Finally, we were unable to identify mechanisms for why the disparity in care intensity was observed at safety-net hospitals but not non-safety-net hospitals. Future research with more detailed information on safety-net hospitals may help explain lower levels of procedure rates for homeless patients.

\section{CONCLUSION}

We found disparities in cardiovascular procedure rates between hospitalised homeless versus non-homeless adults at safety-net hospitals but not at non-safety-net hospitals. Identifying the mechanisms leading to these disparities may lead to improved care for homeless patients.

\section{Author affiliations}

${ }^{1}$ Department of Public Health, Graduate School of Medicine, The University of Tokyo, Bunkyo-ku, Tokyo, Japan

${ }^{2}$ Health Services Research and Development Center, University of Tsukuba, Tsukuba, Ibaraki, Japan

${ }^{3}$ Department of Population Health Sciences, Weill Cornell Medicine, New York, New York, USA

${ }^{4}$ Department of Medicine, Weill Cornell Medicine, New York, New York, USA ${ }^{5}$ Division of General Internal Medicine and Health Services Research, University of California Los Angeles David Geffen School of Medicine, Los Angeles, California, USA

${ }^{6}$ Department of Health Policy and Management, UCLA Fielding School of Public Health, Los Angeles, California, USA

Twitter Atsushi Miyawaki @AMiyawaki38, Dhruv Khullar @DhruvKhullar and Yusuke Tsugawa @ytsugawa1

Contributors AM had full access to the data in the study and takes responsibility for the accuracy and integrity of the data and its analyses. All authors contributed to study concept and design; acquisition, analysis or interpretation of data; drafting of the manuscript; critical revision of the manuscript for important intellectual content and statistical analysis. YT obtained funding; administrative, technical or material support; and study supervision.

Funding This study was supported by St Luke's International University, Tokyo, Japan (Award/Grant number is not applicable). YT was supported by NIH/NIMHD Grant R01MD013913 and NIH/NIA Grant R01AG068633 for other work not related to this study. The funder did not participate in the research or review any details of this study.

Competing interests None declared.
Patient consent for publication Not required.

Ethics approval The study was approved by the UCLA Institutional Review Board. The requirement for written informed consent was waived because all data were blinded.

Provenance and peer review Not commissioned; externally peer reviewed.

Data availability statement Data may be obtained from a third party and are not publicly available. The State Inpatient Database is available upon request to the Agency for Healthcare Research and Quality, and the AHA Annual Survey is available upon request to the American Hospital Association, though the contract does not allow us to share these two datasets. The Medicare Provider Cost Report files are publicly available.

Supplemental material This content has been supplied by the author(s). It has not been vetted by BMJ Publishing Group Limited (BMJ) and may not have been peer-reviewed. Any opinions or recommendations discussed are solely those of the author(s) and are not endorsed by BMJ. BMJ disclaims all liability and responsibility arising from any reliance placed on the content. Where the content includes any translated material, BMJ does not warrant the accuracy and reliability of the translations (including but not limited to local regulations, clinical guidelines, terminology, drug names and drug dosages), and is not responsible for any error and/or omissions arising from translation and adaptation or otherwise.

Open access This is an open access article distributed in accordance with the Creative Commons Attribution Non Commercial (CC BY-NC 4.0) license, which permits others to distribute, remix, adapt, build upon this work non-commercially, and license their derivative works on different terms, provided the original work is properly cited, appropriate credit is given, any changes made indicated, and the use is non-commercial. See: http://creativecommons.org/licenses/by-nc/4.0/.

ORCID iDs

Atsushi Miyawaki http://orcid.org/0000-0001-6126-1464

Yusuke Tsugawa http://orcid.org/0000-0002-1937-4833

\section{REFERENCES}

1 National Coalition for the Homeless. How many people experience homelessness? 2009. Available: https://www.nationalhomeless.org/ factsheets/How_Many.pdf [Accessed 1 Apr 2020].

2 Tsai J, Lifetime TJ. Lifetime and 1-year prevalence of homelessness in the US population: results from the National epidemiologic survey on alcohol and related Conditions-III. J Public Health 2018;40:65-74.

3 US Department of Housing and Urban Development. Criteria and Recordkeeping requirements for definition of homelessness, 2012. Available: https://www.hudexchange.info/resource/1974/criteria-andrecordkeeping-requirements-for-definition-of-homeless/ [Accessed 9 Mar 2020].

4 Fazel S, Geddes JR, Kushel M. The health of homeless people in high-income countries: descriptive epidemiology, health consequences, and clinical and policy recommendations. Lancet 2014;384:1529-40.

5 Jones C, Perera A, Chow M, et al. Cardiovascular disease risk among the poor and homeless - what we know so far. CCR 2009;5:69-77.

6 O'Connell JJ. Premature mortality in homeless populations: a review of literature. National Health Care for the Homeless Council 2005.

7 Baggett TP, Liauw SS, Hwang SW. Cardiovascular Disease and Homelessness. J Am Coll Cardiol 2018;71:2585-97.

8 Baggett TP, Hwang SW, O'Connell JJ, et al. Mortality among homeless adults in Boston: shifts in causes of death over a 15-year period. JAMA Intern Med 2013;173:189.

9 Lee TC, Hanlon JG, Ben-David J, et al. Risk factors for cardiovascular disease in homeless adults. Circulation 2005;111:2629-35.

10 Baggett TP, Rigotti NA. Cigarette smoking and advice to quit in a national sample of homeless adults. Am J Prev Med 2010;39:164-72.

11 Lebrun-Harris LA, Baggett TP, Jenkins DM, et al. Health status and health care experiences among homeless patients in federally supported health centers: findings from the 2009 patient survey. Health Serv Res 2013;48:992-1017.

12 Seale JV, Fallaize R, Lovegrove JA. Nutrition and the homeless: the underestimated challenge. Nutr Res Rev 2016;29:143-51.

13 Hwang SW. Mortality among men using homeless shelters in Toronto, Ontario. JAMA 2000;283:2152.

14 Greysen SR, Allen R, Lucas Gl, et al. Understanding transitions in care from hospital to homeless shelter: a mixed-methods, 
community-based participatory approach. $J$ Gen Intern Med 2012;27:1484-91.

15 Hansen LO, Young RS, Hinami K, et al. Interventions to reduce 30-day rehospitalization: a systematic review. Ann Intern Med 2011;155:520-8.

16 Sadowski LS, Kee RA, VanderWeele TJ, et al. Effect of a housing and case management program on emergency department visits and hospitalizations among chronically ill homeless adults: a randomized trial. JAMA 2009:301:1771-8.

17 Wadhera RK, Khatana SAM, Choi E, et al. Disparities in care and mortality among homeless adults hospitalized for cardiovascular conditions. JAMA Intern Med 2020;180:357-66.

18 Lukas CV, Holmes S, Harrison M. Can safety-net Hospital systems redesign themselves to achieve financial viability? Available: https:// www.healthaffairs.org/do/10.1377/hblog20150316.045188/full/ [Accessed 30 Mar 2020].

19 Bradley CJ, Dahman B, Shickle LM, et al. Surgery wait times and specialty services for insured and uninsured breast cancer patients: does Hospital safety net status matter? Health Serv Res 2012;47:677-97.

20 Werner RM, Goldman LE, Dudley RA. Comparison of change in quality of care between safety-net and non-safety-net hospitals. JAMA 2008;299:2180-7.

21 Acharya T, Salisbury AC, Spertus JA. In-hospital outcomes of percutaneous coronary intervention in america's safety net. JACC: Cardiovascular Interventions 2017;10:1475-85.

22 Goldman LE, Vittinghoff E, Dudley RA. Quality of care in hospitals with a high percent of Medicaid patients. Med Care 2007;45:579-83.

23 Jha AK, Orav EJ, Li Z, et al. Concentration and quality of hospitals that care for elderly black patients. Arch Intern Med 2007;167:1177.

24 Ross JS, Bernheim SM, Lin Z, et al. Based on key measures, care quality for Medicare enrollees at safety-net and non-safety-net hospitals was almost equal. Health Aff 2012;31:1739-48.

25 Ross JS, Cha SS, Epstein AJ, et al. Quality of care for acute myocardial infarction at urban safety-net hospitals. Health Aff 2007;26:238-48.

26 The Healthcare Cost and Utilization Project. HCUP-US SID overview, 2020. Available: https://www.hcup-us.ahrq.gov/sidoverview.jsp [Accessed 26 Mar 2020].

27 Andrews RM. Statewide hospital discharge data: collection, use, limitations, and improvements. Health Serv Res 2015;50 Suppl 1:1273-99.

28 Yamamoto A, Needleman J, Gelberg L, et al. Association between homelessness and opioid overdose and opioid-related Hospital admissions/emergency department visits. Soc Sci Med 2019;242:112585.

29 Henry M, Mahathey A, Morrill T. The 2018 annual homeless assessment report (AHAR) to Congress, part 1: Point-in-Time estimates of homelessness. The U.S. Department of Housing and Urban Development 2018.

30 Centers for Medicare \& Medicaid Services. HCRIS Hospital 2010 files. Available: http://downloads.cms.gov/files/hcris/hosp10-reports. zip [Accessed 1 Feb 2020].

31 American Hospital Association. AHA Annual Survey | American Hospital Association's Annual Survey Database | AHA Data Online, 2019. Available: https://www.ahadataviewer.com/additional-dataproducts/AHA-Survey/ [Accessed 1 Apr 2020].
32 Centers for Medicare \& Medicaid Services. Measure methodology, 2020. Available: https://www.cms.gov/Medicare/Quality-InitiativesPatient-Assessment-Instruments/HospitalQualitylnits/MeasureMethodology [Accessed 8 Feb 2021].

33 Karaca Z, Wong HS, Mutter RL. Characteristics of homeless and non-homeless individuals using inpatient and emergency department services, 2008. U.S. Agency for Healthcare Research and Quality 2013 https://www.ncbi.nlm.nih.gov/books/NBK137747/pdf/ Bookshelf NBK137747.pdf (accessed 1 Apr 2020).

34 Sun R, Karaca Z, Wong HS. Characteristics of homeless individuals using emergency department services in 2014. U.S. agency for healthcare research and quality, 2017. Available: https://www.hcupus.ahrq.gov/reports/statbriefs/sb229-Homeless-ED-Visits-2014.pdf [Accessed 1 Apr 2020].

35 Wadhera RK, Choi E, Shen C, et al. Trends, causes, and outcomes of hospitalizations for homeless individuals: a retrospective cohort study. Med Care 2019;57:21-7.

36 Center for Medicare \& Medicaid Services. Disproportionate share Hospital (DSH) CMS.pdf. Available: https://www.cms.gov/Medicare/ Medicare-Fee-for-Service-Payment/AcutelnpatientPPS/dsh [Accessed 1 Apr 2020].

37 Popescu I, Fingar KR, Cutler E, et al. Comparison of 3 safety-net Hospital definitions and association with Hospital characteristics. JAMA Netw Open 2019;2:e198577.

38 Moore BJ, White S, Washington R, et al. Identifying increased risk of readmission and in-hospital mortality using Hospital administrative data. Med Care 2017;55:8:703-5.

39 Wooldridge JM. Econometric Analysis of Cross Section and Panel Data. Cambridge, Mass: MIT Press, 2010.

40 Williams R. Using the margins command to estimate and interpret adjusted predictions and marginal effects. Stata J 2012;12:308-31.

41 Brand CA, Barker AL, Morello RT, et al. A review of hospital characteristics associated with improved performance. Int J Qual Health Care 2012;24:483-94.

42 Figueroa JF, Joynt KE, Zhou X, et al. Safety-Net hospitals face more barriers yet use fewer strategies to reduce readmissions. Med Care 2017;55:229-35.

43 Jha AK, DesRoches CM, Shields AE, et al. Evidence of an emerging digital divide among hospitals that care for the poor. Health Aff 2009;28:w1160-70.

44 Chatterjee P, Joynt KE, Orav EJ, et al. Patient experience in safetynet hospitals: implications for improving care and value-based purchasing. Arch Intern Med 2012;172:1204.

45 Miyawaki A, Hasegawa K, Figueroa JF, et al. Hospital readmission and emergency department revisits of homeless patients treated at homeless-serving hospitals in the USA: observational study. $J$ Gen Intern Med 2020;35:2560-8.

46 O'Gara PT, Kushner FG, Ascheim DD. ACCF/AHA guideline for the management of ST-elevation myocardial infarction. J Am Coll Cardiol 2013;2013:e78:138-40.

47 Powers WJ, Derdeyn CP, Biller J. American heart Association/ American stroke association focused update of the 2013 guidelines for the early management of patients with acute ischemic stroke regarding endovascular treatment: a guideline for healthcare professionals from the American heart Association/American stroke association. Stroke 2015;2015:3020-35. 